\title{
DETERMINAÇÃO DA VULNERABILIDADE DO AQUÍFERO BASÁLTICO NO CAMPUS DA UFMS, EM CAMPO GRANDE - MS
}

\author{
Vulnerability Assesment of the Basaltic Aquifer at UFMS's Campus at Campo Grande-MS. \\ Cristine Hortência Coutinho Pontes ${ }^{1}$, Giancarlo Lastoria², Antonio Conceição Paranhos Filho ${ }^{3}$, \\ Sandra Garcia Gabas ${ }^{4}$ e Paulo Tarso Sanches de Oliveira ${ }^{5}$
}

\begin{abstract}
RESUMO: $\quad$ O Campus da Universidade Federal de Mato Grosso do Sul (UFMS) em Campo Grande está localizado na bacia do córrego Bandeira e possui um sistema próprio de abastecimento de água, alimentado pelo Aquífero Basáltico da Formação Serra Geral. Devido à importância desse manancial para o Campus e região, dois métodos de avaliação de vulnerabilidade de aquíferos - GOD e DRASTIC foram aplicados. Os métodos são ferramentas auxiliares para a tomada de decisão em planejamento urbano ou zoneamento ecológico-econômico, bases para o gerenciamento integrado dos recursos naturais e não substituem as campanhas de campo e monitoramentos no local. No mapa gerado pelo método GOD obteve-se três áreas - de baixa, média e alta vulnerabilidade, enquanto que no mapa produzido pelo método DRASTIC tem-se quatro graus de vulnerabilidade - de muito baixa a alta, passando pelos graus de vulnerabilidade baixa e moderada. Ambos os métodos apresentaram coerência com relação às áreas de alta e baixa vulnerabilidade. Com base nestes resultados, poderá ser incrementada a gestão dos recursos hídricos no Campus, enfatizando que os métodos podem ser aplicados em outras áreas do Estado, inclusive na ocorrência de outros aquíferos. A otimização deste trabalho requer a intensificação do levantamento de dados do meio físico, dos focos contaminantes e o monitoramento do aquífero para que eventos de contaminação possam ser prontamente identificados e atenuados garantindo a preservação do recurso natural.
\end{abstract}

Palavras-Chave: Vulnerabilidade, Aquífero Serra Geral, Campus da UFMS

ABSTRACT: The Federal University of Mato Grosso do Sul Campus (UFMS) is located at Campo Grande in the basin of the Bandeira stream. It has its own water well supply system from the basalts of Serra Geral Aquifer. Due to the importance of this water source for the Campus and the region, two methods of aquifer vulnerability assessment - DRASTIC and GOD - were applied. The methods are auxiliary tools for the decision process in issues such as urban planning and economic-ecological zoning which are the basis for the integrated management of the natural resources. However, the methods do not substitute the field trips and the local monitoring. In the GOD map, it was observed three areas of low, medium and high vulnerability, while in the DRASTIC map it was obtained four levels of vulnerability - from very low, low, moderate and high vulnerability. Both methods are coherent about the high and low vulnerability areas. According to the results, a better management plan could be developed at Campus and both methods can be applied to other areas of the State, including other aquifers. To optimize this project, it is necessary to intensify the data collection from environment, contaminant sources and also settle an aquifer monitoring program, in order to prevent contaminant events.

Key-words: Vulnerability, Serra Geral Aquifer, UFMS's Campus

\section{INTRODUÇ̃̃O}

O recurso hídrico subterrâneo vem sendo explorado em grande volume não somente nas regiões sul e sudeste do Brasil, mais populosas, mas também em outras partes do país. Este fato é consequência do aumento da demanda pela água e da falta de gerenciamento do recurso hídrico superficial que se encontra atualmente em grande parte degradado por poluição doméstica, agrícola e industrial, como também por grandes volumes de sedimentos inconsolidados carreados e depositados nos corpos d'água.

A partir deste último cenário, percebe-se a necessidade de muito trabalho em termos de recuperação dos rios e fontes que abasteciam até então muitas cidades brasileiras. No entanto, isso demanda tempo, políticas de proteção e gerenciamento bem delineadas, além de mudança de comportamento não somente dos grandes setores da economia, como também de usuários comuns, ainda com a mentalidade que o recurso hídrico é infinito. Com isso, o recurso subterrâneo vem se tornando a melhor alternativa para abastecimento de áreas urbanas, rurais e setores industriais.

A vulnerabilidade de aquíferos é abordada neste trabalho com a aplicação de dois métodos DRASTIC e GOD - em uma área piloto de grande utilidade no Estado, visto que guarda em seu território aquíferos de importância não somente estadual, mas que ultrapassam as fronteiras internacionais, tais como o Sistema Aquífero Guarani -SAG e o Sistema Aquífero Serra Geral -SASG, de naturezas distintas, bem como com diferentes graus de uso e ocupação das superfícies de suas áreas de ocorrência. Os métodos aplicados são ferramentas que auxiliam na tomada de decisão quanto aos programas de gerenciamento.

Não existe literatura referente à aplicação dos métodos no âmbito do Estado do Mato Grosso do Sul. São ferramentas preliminares de baixo custo, que podem ser aplicadas tanto em uma

1(cristinepontes@gmail.com)2(lastoria@nin.ufms.br)3(paranhos@nin.ufms.br)4(sandra.gabas@uol.com.br)

s(paulotarso@nin.ufms.br) 
região extensa como a do Estado, quanto em áreas menores como a do Campus, que necessitam estabelecer, entre outros programas, um projeto de proteção de seus aquíferos.

\section{ÁREA DE ESTUDO}

A área de estudo localiza-se na capital do Estado, no Campus da Universidade Federal de Mato Grosso do Sul (UFMS), com aproximadamente 160 ha; abrange parte da bacia do Córrego Bandeira, e seu afluente Cabaça, até o exutório no Lago do Amor (Figura 1). A Bacia do Córrego Bandeira é contribuinte do Rio Anhanduí que pertence à Sub-Bacia do rio Pardo, afluente da margem direita da bacia do Rio Paraná, que ocupa a parte oriental do Estado de Mato Grosso do Sul.

A região do Campus passou por algumas modificações: o Lago do Amor e toda a topografia do Campus é uma adaptação das condições físicas do terreno para o estabelecimento da Universidade e bairros ao seu redor.

Dentro do Campus existem laboratórios, hospitais, incluindo um Hospital Veterinário, uma área de preservação (RPPN - Reserva Particular de Patrimônio Natural) e outras instalações tais como estádio de futebol, piscinas e um projeto de piscicultura. Ao seu redor existe uma intensa atividade comercial relacionada à instalação de empresas de ônibus, supermercados, uma região residencial, indústria de bebida (Coca-Cola), um Instituto Médico Legal - IML e um cemitério.

Ainda no Campus (Fernando Assato, Gerência de Projetos e Obras da UFMS - 2008, comunicação pessoal) todo o setor a norte-nordeste do Lago do Amor, onde está a maior parte dos prédios do Campus, é provido de sistema de coleta de esgoto e de tratamento, enquanto que a porção sulsudoeste do lago (Departamento de Química, por exemplo) é provido de fossa sumidouro em todos os prédios. Por outro lado, quase todo o Campus é servido de água de poços tubulares ali instalados, com exceção do Setor de Hemodiálise do Hospital Universitário (HU) que é abastecido pelo único ponto de abastecimento tratado servido pela Companhia de Abastecimento Águas Guariroba. Dos sete poços cadastrados no Campus, existe um único poço tubular desativado localizado ao lado do Teatro Glauce Rocha. Outros seis poços suprem o abastecimento e existem outros ao redor que também exploram o Aquífero Serra Geral.

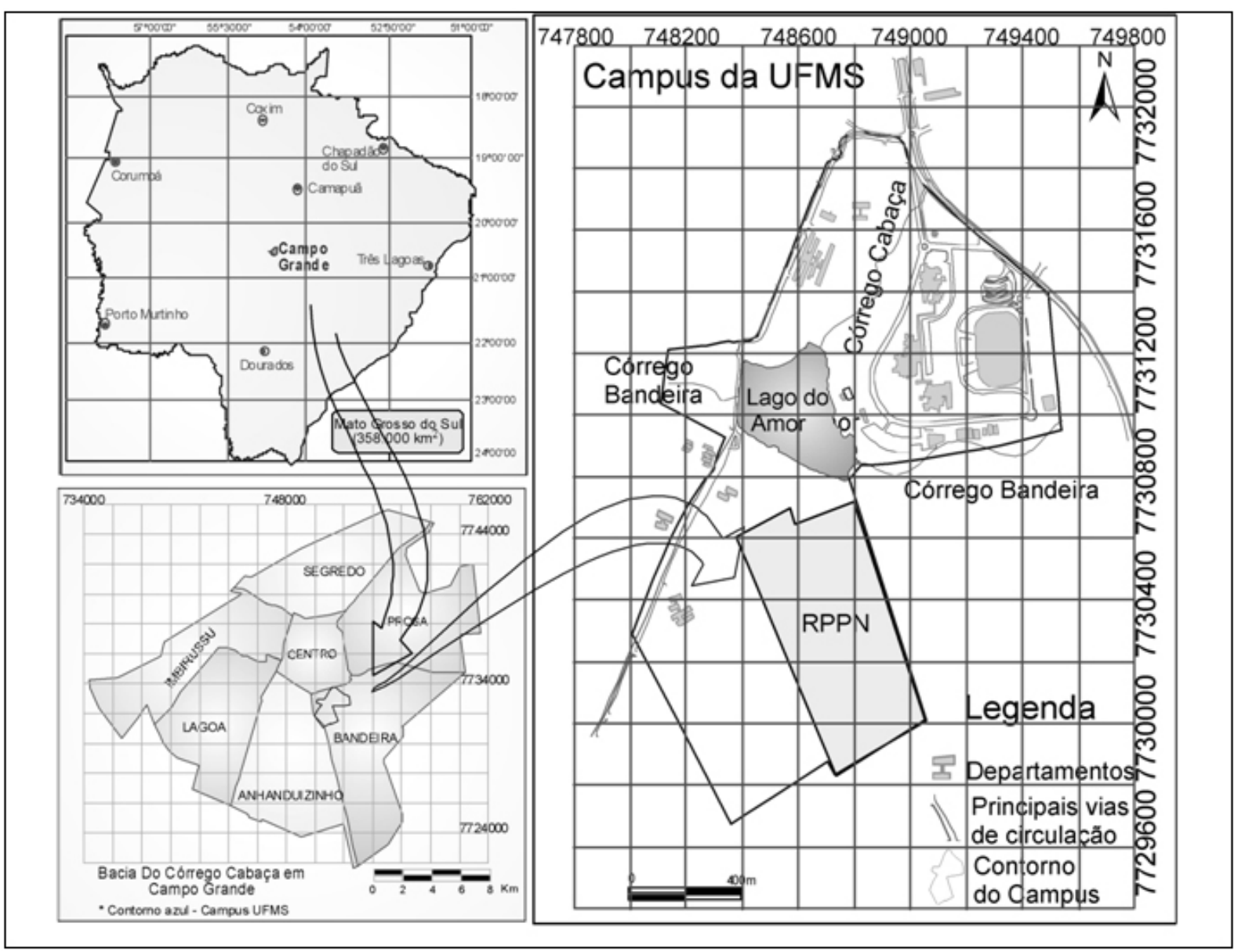

Figura 1: Localização da área de estudo. (Fonte: Modificado de OLIVEIRA, 2003.)

Figure 1: Location of the studied area (Modified from OLIVEIRA (2003)). 
O Campus é uma área urbana planejada. No entanto, o crescimento da cidade fora dos seus limites, incluindo o excesso de poços tubulares instalados, prejudica a capacidade do próprio Campus quanto ao gerenciamento da sua infraestrutura.

Segundo informação por circular interna (CI n. 125/2009 GAB/PRAD), há cerca de 10.000 pessoas que circulam no Campus diariamente que dependem de água captada por poços. Outra circular (CI n. 030/2008-NHU) informa que aproximadamente 2100 pessoas circulam por dia pelo Hospital Universitário, entre pacientes internados, em consulta, servidores, residentes e médicos docentes.

\section{CARACTERIZAÇÃO DAÁREA DE ESTUDO}

\section{Contexto Geológico}

A área do Projeto insere-se na borda oeste da Bacia Sedimentar do Paraná, especificamente sobre basaltos da Formação Serra Geral do Grupo São Bento. Sotopostos às rochas basálticas, encontram-se os arenitos da Formação Botucatu, típicos de ambiente desértico, com grande potencial hídrico - Sistema Aquífero Guarani (SAG). No Campus, foram identificadas ocorrências deste aquífero em alguns poços estudados, a partir de $60 \mathrm{~m}$ de profundidade.

De acordo com os perfis dos poços perfurados pela própria Universidade para abastecimento do Campus, o contato de base dos derrames basálticos ocorre entre 60 e mais de $115 \mathrm{~m}$ de profundidade (informação de poço sem ter atingido a Formação Botucatu). Os basaltos apresentam estrutura maciça em sua maior extensão e os níveis vesiculares/ amigdaloidais localizam-se predominantemente entre 30 e $45 \mathrm{~m}$ de profundidade. A espessura do manto de alteração varia entre 24 e $35 \mathrm{~m}$. Segundo Lastoria (2002), a espessura dos basaltos na região de Campo Grande pode alcançar até 300 metros.

Ocorrem, ainda, aluviões recentes sobrepostos ao basalto, com sedimentos arenosos em torno das drenagens, quaternários segundo o Instituto Municipal de Planejamento Urbano - PLANURB (1991).

\section{Geomorfologia}

O Projeto RADAMBRASIL, MME (1982) identificou cinco grandes unidades geomorfológicas no Estado de Mato Grosso do Sul: Planalto da Bodoquena, Depressão do Rio Paraguai, Planalto de Maracaju-Campo Grande, Planície do Rio Paraná, Planícies e Pantanais
Mato-Grossenses.

A área do Projeto localiza-se no contexto geomorfológico referente ao Planalto MaracajuCampo Grande que é ambiente de borda da Bacia Sedimentar do Paraná, marcada pela presença de cuestas, onde afloram rochas do Grupo São Bento. Os basaltos resistem às atuações de denudação e mantém a linha de cuesta que gera no Estado um divisor hidrográfico (bacias do Paraná e do Paraguai) com direção regional N-NE/S-SW (Serra de Maracajú). No geral, o relevo é suave a suave-ondulado.

\section{Solos}

A "Carta Geotécnica para Ocupação Urbana de Campo Grande - MS", na escala 1:20.000 (PLANURB, 1991), descreve a região do Campus com sua porção norte ocupada por solos relacionados aos arenitos intertrapeanos, de classificação Latossolo vermelho amarelo e vermelho escuro, mal drenados, textura média e argilosa, e na parte sul, os solos são típicos de basaltos onde observam-se os Latossolos vermelho escuros de textura média ou argilosa. Há ainda, aproximadamente no centro do Campus, ao longo das drenagens, a ocorrência de solos aluviais.

Os solos sobre os arenitos intertrapeanos, têm alteração de rocha de 5 a $15 \mathrm{~m}$ de profundidade. São solos de textura silte argilo-arenoso, silte arenoso (saibro) com presença constante de concreção ferruginosa. Os solos sobre os basaltos possuem de 1 a $10 \mathrm{~m}$ de espessura; apresentam textura silte argilosa, com possíveis intercalações de blocos e fragmentos de rochas. Os solos próximos às drenagens são em geral argilosos, mal drenados e saturados, pouco espessos, na maioria das situações, assentados sobre basaltos.

Segundo Soares (2004), o solo do Campus apresenta textura areia fina siltosa, com alguns locais de areia fina argilosa, em profundidade de até 1 metro.

\section{Cobertura Vegetal}

A área de estudo do Campus (comunicação pessoal, Prof. Dr. Lastoria) tem 50,1 ha de Reserva Particular do Patrimônio Natural - RPPN, que inclui aproximadamente $45 \mathrm{ha}$ de cerrado, mais 5ha de mata ciliar no córrego Cabaça e parte de vereda no córrego Bandeira a montante do Lago do Amor. O restante da área configura uma descaracterização com relação à vegetação original em função do grau de urbanização pela qual vem passando. 


\section{Hidrogeologia}

O Sistema Aquífero Serra Geral (SASG) (TAHAL/ Empresa de Saneamento de Mato Grosso do Sul - SANESUL, 1998) é uma unidade da Bacia do Paraná que se encontra distribuída na porção centro-leste do Estado com $178.000 \mathrm{~km}^{2}$ de área; $40.000 \mathrm{~km}^{2}$ aflorantes e $138.000 \mathrm{~km}^{2}$ subjacentes aos sedimentos do Grupo Bauru. É um aquífero do tipo fraturado e heterogêneo, sendo mais explorado em sua porção aflorante ou onde a cobertura do Grupo Bauru é pequena. Cidades como Campo Grande, Dourados, Sidrolândia, Caarapó e Ponta Porã são abastecidas, em grande parte, por este aquífero. A área do Campus está instalada sobre este aquífero.

Testes de bombeamento indicam transmissividade de até $1.176 \mathrm{~m}^{2} / \mathrm{dia}$ ou mais comumente $30 \mathrm{~m}^{2} / \mathrm{dia}$. Lastoria (2002) gerou um modelo hidrogeológico para a Formação Serra Geral aflorante na porção oeste da Bacia do Paraná (dentro do Estado de Mato Grosso do Sul) com ênfase nas estruturas horizontais do basalto como as principais e melhores fontes de água subterrânea e não as juntas verticais e sub-verticais, enfatizando para uma característica importante deste aquífero, a anisotropia. As estruturas horizontais, tais como juntas, diaclasamentos na base e topo, além dos próprios contatos interderrames, são os grandes reservatórios de água deste aquífero.

No modelo proposto pela TAHAL/SANESUL (1998) foram estabelecidos valores para a condutividade hidráulica horizontal e vertical do Aquífero Basáltico. O Campus, inserido na área K3 do citado modelo, apresenta os seguintes valores: $\mathrm{Kx}$ - condutividade hidráulica horizontal de 1,0 a 10,0 m/dia e Kz-condutividade hidráulica vertical de 0,13 a $0,001 \mathrm{~m} / \mathrm{dia}$. Tais valores foram obtidos por meio do modelo de regime constante calibrado.

$\mathrm{O}$ estudo considera a precipitação anual sobre a área em questão de $1.400 \mathrm{~mm} / \mathrm{a}$, a partir de dados das estações pluviométricas de Usina Mimoso, Capão Bonito, Nioaque e Aquidauana. Este dado de pluviometria foi confirmado por Lastoria (2002) a partir de dados de série histórica 1961-1990 em posto situado na cidade de Campo Grande, obtidos no Instituto Nacional de Meteorologia - INMET (2000).

$\mathrm{O}$ valor de recarga do Aquífero Basáltico definido pelo estudo da TAHAL/SANESUL (1998) varia de 120,0 a $210,0 \mathrm{~mm} / \mathrm{a}$ o que corresponde a uma faixa de $5-15 \%$ do valor da precipitação anual.

O mapa potenciométrico do aquífero basáltico na área do Campus (Figura 2) indica direções de fluxo (OLIVEIRA, 2003) pelas setas. Observase pela Figura 2 que não há um padrão único de direção. No entanto, há um fluxo bem definido na altura do Córrego Bandeira, na parte central do Campus, de sentido oeste. Observa-se ainda que a porção norte do Campus é a principal área de recarga.

\section{MÉTODO DO ÍNDICE DRASTIC}

O primeiro método utilizado neste estudo apresenta denominação composta pelas primeiras letras de cada um dos sete atributos (em inglês) a serem quantificados:

1. D - depth to water - profundidade do nível d'água;

2. R- net recharge - recarga;

3. A- aquifer media-meio aquífero;

4. S- soil media - solo;

5. T- topography - declividade;

6. I- impact of the vadose zone - material da zona vadosa;

7. C- hydraulic conductivity - condutividade hidráulica.

Este método foi criado nos Estados Unidos pela Agência de Proteção Ambiental NorteAmericana (USEPA) em parceria com Associação Nacional de Água Subterrânea (National Ground Water Association NGWA) por Aller et al. (1987) para padronizar a avaliação de qualquer unidade hidrogeológica com relação ao potencial de poluição, sendo esta considerada como a interação de fatores hidrogeológicos, antropogênicos e fontes de contaminação de uma área qualquer. 


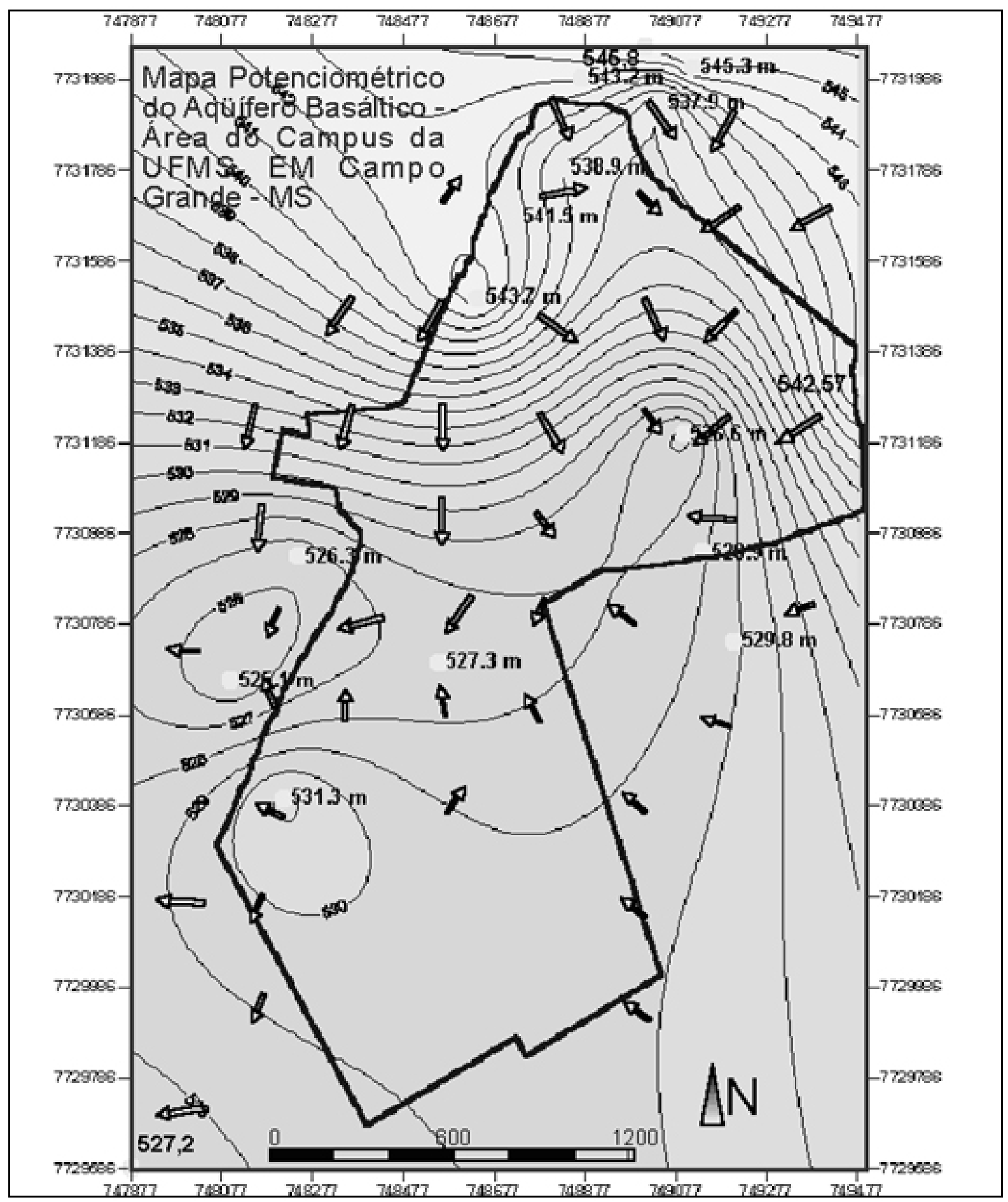

Figura 2: Mapa potenciométrico do aquifero basáltico no Campus da UFMS em Campo Grande, MS (Fonte: OLIVEIRA, 2003.).

Figure 2: Potenciometric map from basaltic aquifer at UFMS Campus at Campo Grande, MS. (OLIVEIRA, 2003.). 
$\mathrm{O}$ método tem como vantagem a utilização de dados existentes para o Campus e modela situações na superfície da Terra por aplicação de contaminantes que se movem por meio aquoso. Cada parâmetro recebe um peso (Tabela 1) que não pode ser modificado e cada parâmetro recebe ainda uma especificação em faixas de ocorrência associada a uma nota (de 1 a 10) que varia de região para região estudada e que implica numa posição de relatividade entre os fatores analisados. O método não substitui pesquisas de campo, mas permite que haja comparações entre áreas com relação aos aspectos de hidrogeologia estudados. Áreas maiores que 100 acres (aproximadamente $0,405 \mathrm{~km}^{2}$ ) são as recomendações para a aplicação deste método e cada nível aquífero deve ser retratado em separado.

Tabela 1: Pesos relativos a cada parâmetro abordado - DRASTIC.

Table 1: Respective weights for DRASTIC parameters.

\begin{tabular}{|c|c|}
\hline Parâmetros & Pesos Relativos (p) \\
\hline D- depth to water - profundidade do nível d'água & 5 \\
\hline R- net recharge - recarga & 4 \\
\hline A- aquifer media - meio aquífero & 3 \\
\hline S- soil media - solo & 2 \\
\hline T- topography - declividade & 1 \\
\hline I- impact of the vadose zone - material da zona vadosa & 5 \\
\hline C- hydraulic conductivity - condutividade hidráulica & 3 \\
\hline Fonte: ALLER et al. (1987).
\end{tabular}

A seguinte equação representa a ponderação de cada parâmetro no resultado final:

$$
\begin{gathered}
\mathrm{Dp} * \mathrm{Dn}+\mathrm{Rp} * \mathrm{Rn}+\mathrm{Ap} * \mathrm{An}+\mathrm{Sp} * \mathrm{Sn}+\mathrm{Tp} * \mathrm{Tn}+\mathrm{Ip} * \mathrm{In}+ \\
\mathrm{Cp}{ }^{*} \mathrm{Cn}=\text { vulnerabilidade }
\end{gathered}
$$

onde as letras maiúsculas são os parâmetros, $p$ é o peso e $n$ a nota para cada um analisado.

Existem valores máximo e mínimo definidos originalmente que traduzem os graus de vulnerabilidade (Tabela 2).

Tabela 2: Classes de vulnerabilidade no método DRASTIC.

Table 2: DRASTIC vulnerability grade ranges.

\begin{tabular}{|c|c|}
\hline Valores Correspondentes & Intervalos de Vulnerabilidade \\
\hline$<100$ & Vulnerabilidade insignificante \\
\hline $101-119$ & Vulnerabilidade muito baixa \\
\hline $120-139$ & Vulnerabilidade baixa \\
\hline $140-159$ & Vulnerabilidade moderada \\
\hline $160-179$ & Vulnerabilidade alta \\
\hline $180-199$ & Vulnerabilidade muito alta \\
\hline$>200$ & Vulnerabilidade extrema \\
\hline Fonte: ALLER et al. $(1987)$.
\end{tabular}

\section{MÉTODO DO ÍNDICE GOD}

Este método foi desenvolvido por Foster (1987) e Foster \& Hirata (1988) e prioriza o tipo de atividade instalada, onde o perigo de contaminação é definido como a interação entre a intensidade da carga antrópica e a vulnerabilidade do aquífero ou ainda para os mananciais de água potável, da sua interação entre o perímetro de proteção do poço ou manancial e as cargas contaminantes que estejam localizadas nas áreas próximas à captação.

O método GOD considera a avaliação de três parâmetros referentes à capacidade de atenuação e a inacessibilidade hidráulica dos poluentes:

1. Grau de confinamento do aquífero $(\mathrm{G}-$ groundwater occurrence), que faz a descrição do tipo de aquífero (não confinado, confinado não drenante ou confinado drenante), em valores dentro de um intervalo de 0 a 1 ;

2. Ocorrência de estratos de cobertura do aqǘfero - natureza composicional da zona não saturada e/ou aquitardo e seu grau de confinamento (O - overall aquifer class), em valores de 0,3 a 1,0;

3. Profundidade do nível d'água ou da base da camada confinante do aquífero (D - depth to groundwater table), em quatro intervalos entre $<5$ $\mathrm{m}$ e $>100 \mathrm{~m}$, na escala de 0,3 a 0,9 .

A seguinte equação representa cada parâmetro 
no resultado final

$\mathrm{G} \times \mathrm{O} \times \mathrm{D}=$ vulnerabilidade,

onde cada parâmetro tem uma nota associada.
Após a pontuação das três etapas acima é feito o produto dos valores obtendo-se a(s) classe(s) de vulnerabilidade do aquífero, os quais deverão ser classificados de acordo com os intervalos de significância representados na Tabela 3 .

Tabela 3: Classes de vulnerabilidade no método GOD.

Table 3: GOD vulnerability grade ranges.

\begin{tabular}{|c|c|}
\hline Intervalo de Classe & Características \\
\hline $0-0,1$ Insignificante & $\begin{array}{c}\text { Desconsidera as camadas confinantes com fluxos verticais descendentes } \\
\text { não significativos. }\end{array}$ \\
\hline 0,1-0,3 Baixo & $\begin{array}{c}\text { Vulnerável a contaminantes conservativos em longo prazo, quando } \\
\text { continuamente e amplamente lançado. }\end{array}$ \\
\hline 0,3-0,5 Médio & $\begin{array}{l}\text { Vulnerável a alguns poluentes, mas somente quando continuamente } \\
\text { lançado. }\end{array}$ \\
\hline $0,5-0,7$ Alto & $\begin{array}{l}\text { Vulnerável a muitos poluentes, exceto aqueles muito pouco móveis e } \\
\text { pouco persistentes. }\end{array}$ \\
\hline 0,7 - 1,0 Extremo & $\begin{array}{l}\text { Vulnerável a muitos poluentes, com rápido impacto em muitos cenários } \\
\text { de contaminação. }\end{array}$ \\
\hline
\end{tabular}

Fonte: FOSTER (1987).

\section{MATERIAIS E MÉTODOS}

Os estudos de vulnerabilidade da área do Campus foram efetuados a partir de informações de dezesseis poços tubulares situados na área da Universidade e suas vizinhanças e de estudos geológicos e hidrogeológicos efetuados anteriormente, bem como de caracterização dos solos. Os dados de localização, cota e nível estático dos poços e as fontes de informações geológicas e hidrogeológicas são apresentados, respectivamente, nas Tabelas 4 e 5. Na Figura 3 estão localizados os poços tubulares e os pontos de caracterização das amostras de solo. Trata-se de uma imagem IKONOS (SPACE IMAGING, 2006), também utilizada para a interpretação das características do substrato, que foi adquirida em abril de 2006 e está fusionada, com resolução de 1 metro.

Tabela 4: Dados dos poços tubulares observados na área do Campus da UFMS e seu entorno.

Table 4: Data from the wells from the University area and surroundings.

\begin{tabular}{|c|c|c|c|c|c|}
\hline Ponto & \multicolumn{2}{|c|}{ Coordenadas UTM } & Cota $(\mathbf{m})$ & NE*$^{*}(\mathbf{m})$ & Cota NE** $(\mathbf{m})$ \\
\hline & $\mathbf{X}(\mathbf{m})$ & $\mathbf{Y}(\mathbf{m})$ & & & \\
\hline 1 & 749139 & 7730944 & 534,50 & 5,60 & 528,90 \\
\hline 2 & 749094 & 7731204 & 542,30 & 15,70 & 526,60 \\
\hline 3 & 748829 & 7731793 & 546,90 & 8,00 & 538,90 \\
\hline 4 & 748641 & 7731507 & 544,40 & 0,70 & 543,70 \\
\hline 5 & 748723 & 7731685 & 545,50 & 4,00 & 541,50 \\
\hline 6 & 748554 & 7730703 & 535,40 & 8,10 & 527,30 \\
\hline 7 & 748213 & 7730403 & 543,40 & 12,10 & 531,30 \\
\hline 8 & 749480 & 7731310 & 554,70 & 12,13 & 542,57 \\
\hline 9 & 749045 & 7731935 & 552,50 & 14,60 & 537,90 \\
\hline 10 & 748244 & 7730936 & 531,30 & 5,00 & 526,30 \\
\hline 11 & 748098 & 7730661 & 537,10 & 12,00 & 525,10 \\
\hline 12 & 749010 & 7732060 & 554,50 & 8,70 & 545,80 \\
\hline 13 & 748868 & 7731990 & 551,20 & 8,00 & 543,20 \\
\hline 14 & 749115 & 7732014 & 554,30 & 9,00 & 545,30 \\
\hline 15 & 749206 & 7730747 & 534,40 & 4,60 & 529,80 \\
\hline 16 & 747877 & 7729586 & 543,00 & 16,00 & 527,20 \\
\hline
\end{tabular}

Coordenadas em UTM, fuso 21, SAD 69. * Nivel estático. ** Cota do nivel estático. Fonte: Adaptado de OLIVEIRA, 2003. 


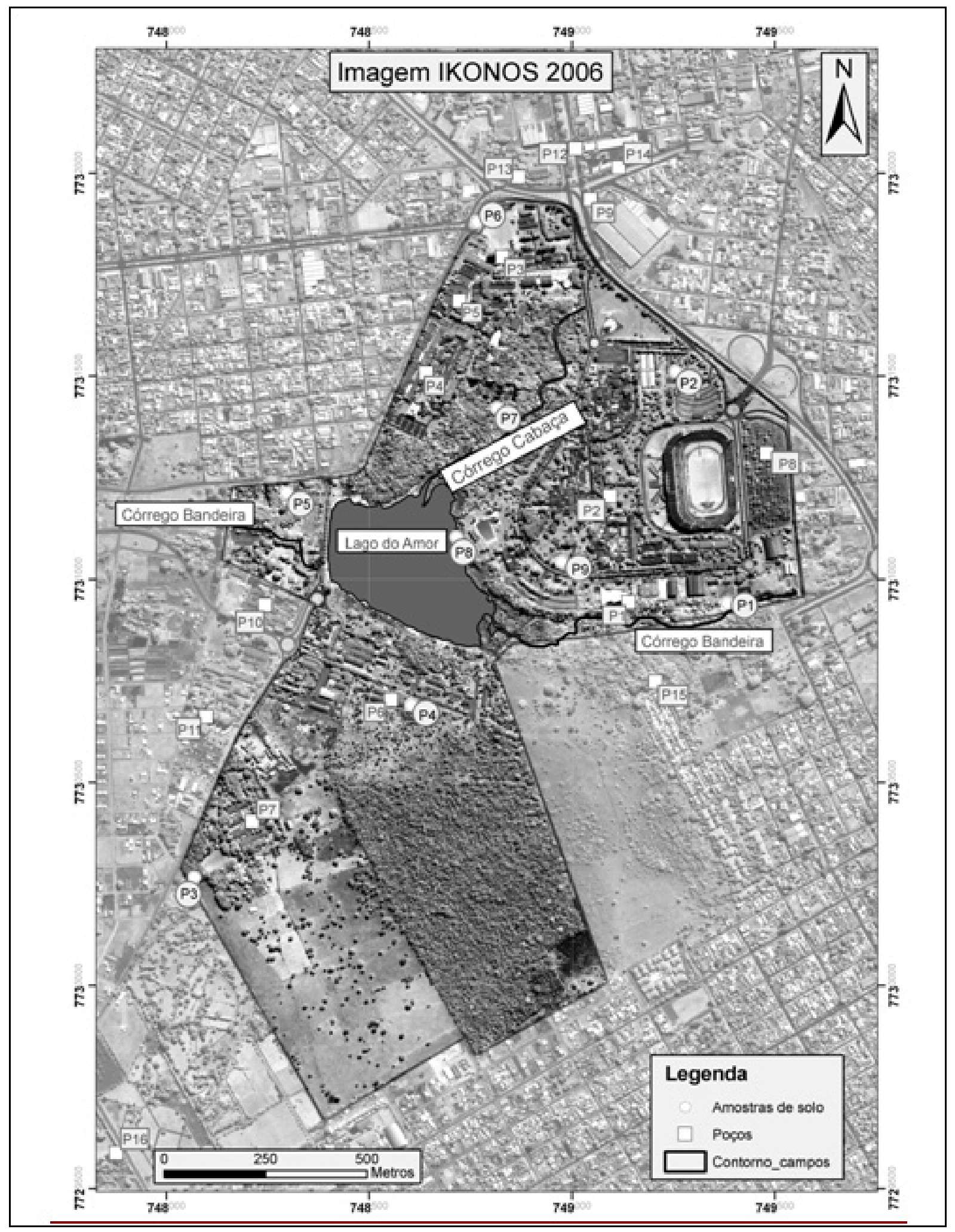

Figura 3: Localização dos poços tubulares e dos pontos de amostragem de solo.

Figure 3: Well and soil sample location map. 
Tabela 5: Materiais utilizados na determinação da vulnerabilidade da área estudada.

Table 5: Data utilized in the vulnerability evaluation of the study area.

\begin{tabular}{|c|c|c|c|}
\hline Material & Escala & Procedência & Finalidade \\
\hline Mapa topográfico & $1: 2.000$ & Oliveira (2003) & Caracterização da declividade. \\
\hline Mapa geológico-geotécnico & $1: 20.000$ & PLANURB (1991) & Caracterização do substrato. \\
\hline Mapa potenciométrico do aquífero & $1: 2.000$ & Oliveira (2003) & $\begin{array}{c}\text { Caracterização do } \\
\text { direcionamento de fluxo. }\end{array}$ \\
\hline $\begin{array}{l}\text { Caracterização granulométrica do } \\
\text { solo }\end{array}$ & $1: 2.000$ & Soares (2004) & Caracterização textural do solo. \\
\hline
\end{tabular}

Os dados relacionados às características do aquífero foram obtidos no estudo da TAHAL/ SANESUL (1998), que aplicou um modelo específico para a cidade de Campo Grande. A condutividade hidráulica adotada foi a vertical de $0,001 \mathrm{~m} / \mathrm{dia}$. Para a recarga, adotou-se o valor de $120 \mathrm{~mm} / \mathrm{a}$ que corresponde a $8,5 \%$ (valor considerado para rochas basálticas) do valor total da precipitação anual de $1400 \mathrm{~mm} / \mathrm{a}$, taxa também empregada no Plano Estadual de Recursos Hídricos (Secretaria de Estado do Meio Ambiente, do Planejamento, da Ciência e Tecnologia e Instituto de Meio Ambiente de Mato Grosso do Sul - SEMAC, 2010).

A partir das informações coletadas e de posse da imagem IKONOS II (SPACE IMAGING, 2006), utilizou-se o programa ArcGIS (ESRI, 2008) para a digitalização dos dados coletados, bem como para a interpretação da imagem de satélite IKONOS II, op cit.

Cada informação ou parâmetro, nos dois métodos, corresponde a um tema, o qual foi transformado em uma camada ou layer. Os dados de profundidade do nível d'água, por exemplo, foram organizados de acordo com as tabelas de valoração de cada método, produzindo dois mapas com diferentes intervalos de profundidade (Figura $6 a$ e $6 b)$.

Para cada camada foi criada uma tabela, denominada pelo programa como tabela de atributos, com a valoração específica dos parâmetros de cada método, como apresentadas nas Figuras 4 e 5 a.

A Figura 4 apresenta um exemplo de valores dos parâmetros do método GOD, circundados em negrito, adotados no cálculo do índice de vulnerabilidade de uma porção da área de estudo, a qual foi classificada, de acordo com a Tabela 3, na classe de alta vulnerabilidade. Da mesma forma, na Figura 5a são apresentados os valores dos parâmetros do método DRASTIC, cujo índice de vulnerabilidade foi classificado, de acordo com a Tabela 2, também na classe de alta vulnerabilidade. A Figura $5 \mathrm{~b}$ apresenta os parâmetros no meio físico.

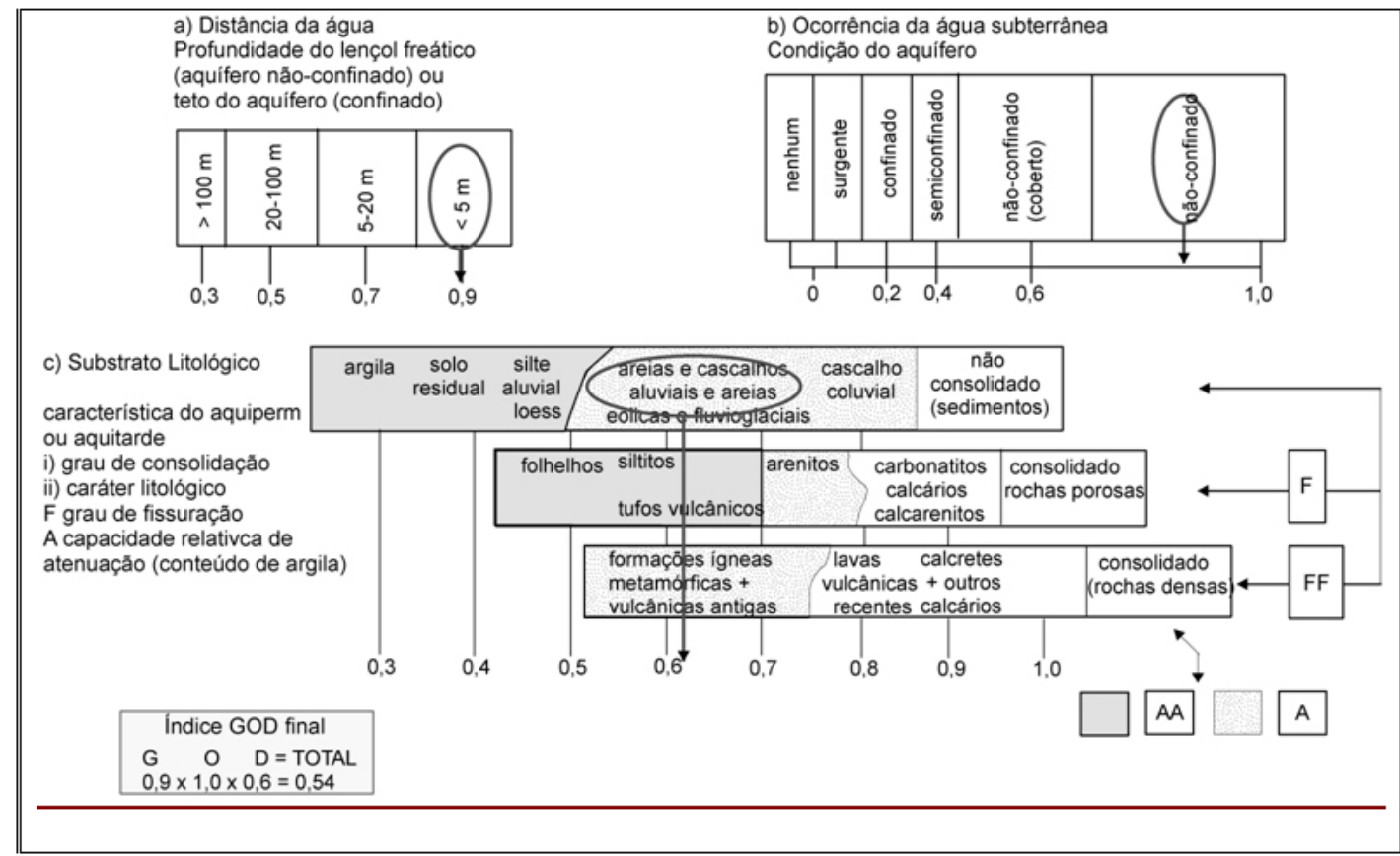

Figura 4: Método de vulnerabilidade GOD e exemplo de valores dos parâmetros adotados para o aquífero na área de estudo (Modificado de HIRATA e FERNANDES, 2008).

Figure 4: GOD vulnerability method and an example of the adopted aquifer parameter values in the study area (Modified from HIRATA e FERNANDES, 2008). 
O mapa de vulnerabilidade foi construído em outra camada, a partir do cruzamento das camadas (álgebra de mapas) de cada método. No caso do
GOD, efetuou-se a multiplicação das camadas e no caso do DRASTIC, a soma.

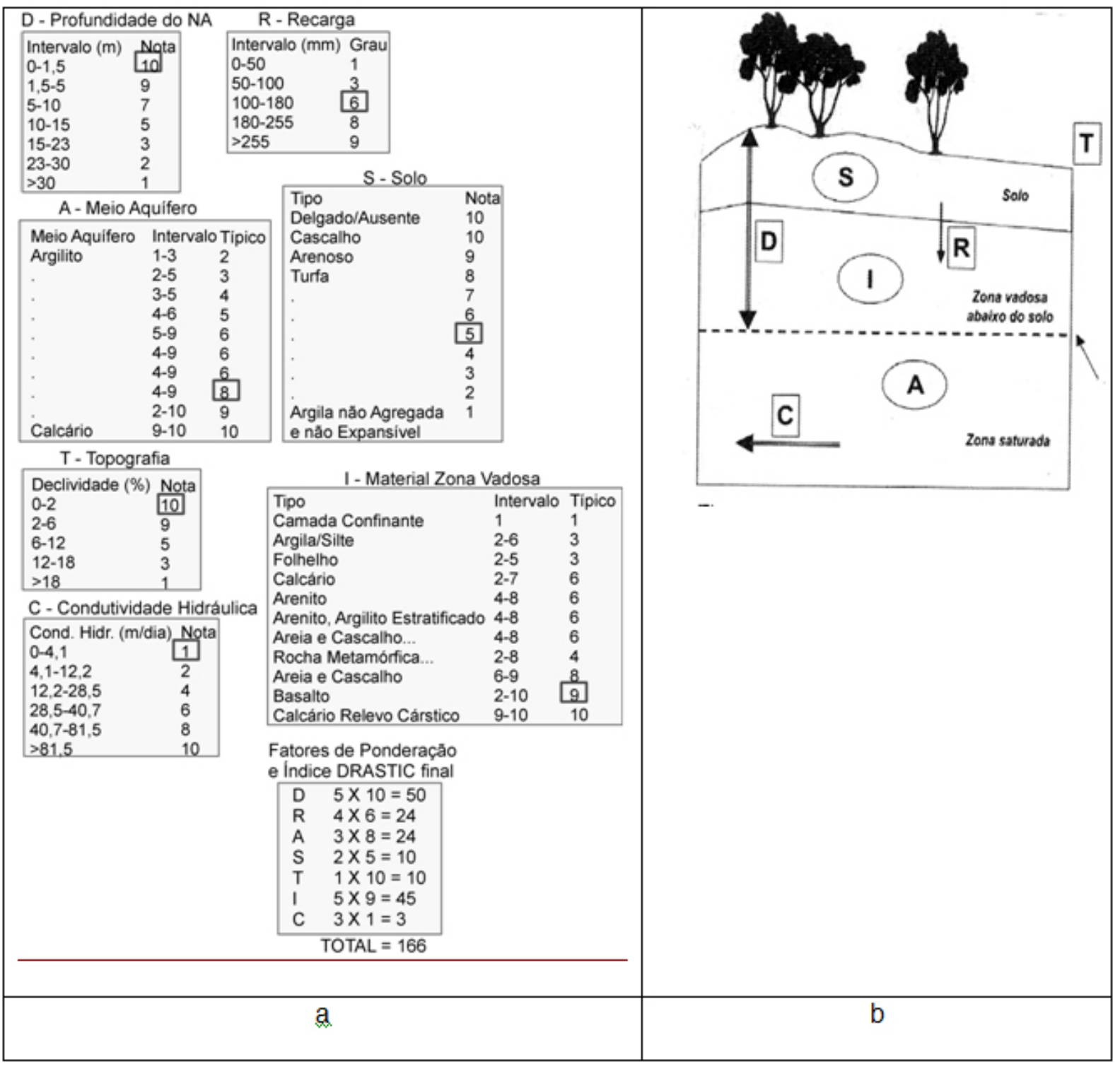

Figura 5: Método de vulnerabilidade DRASTIC e exemplo de valores (a) dos parâmetros (b) adotados para o aquifero na área de estudo (Modificado de HIRATA e FERNANDES, 2008).

Figure 5: DRASTIC vulnerability method and an example of the adopted aquifer parameter (b) values (a) in the study area. (Modified from HIRATA e FERNANDES, 2008.) 


\section{RESULTADOS E DISCUSSÕES}

As Figuras 6 a 8 apresentam alguns dos parâmetros utilizados nos métodos, com a interpretação dos dados coletados, cujas representações em mapas são inéditas para o Campus. A Figura 9 apresenta o resultado do estudo de vulnerabilidade de acordo com os dois métodos utilizados.
Observa-se, nas Figuras $6 a$ e $6 b$, uma semelhança na configuração dos contornos das classes de profundidade do nível d'água nas porções sul e oeste do Campus. A porção sul caracteriza-se por apresentar profundidades maiores do nível d'água e a porção oeste apresenta profundidades menores.

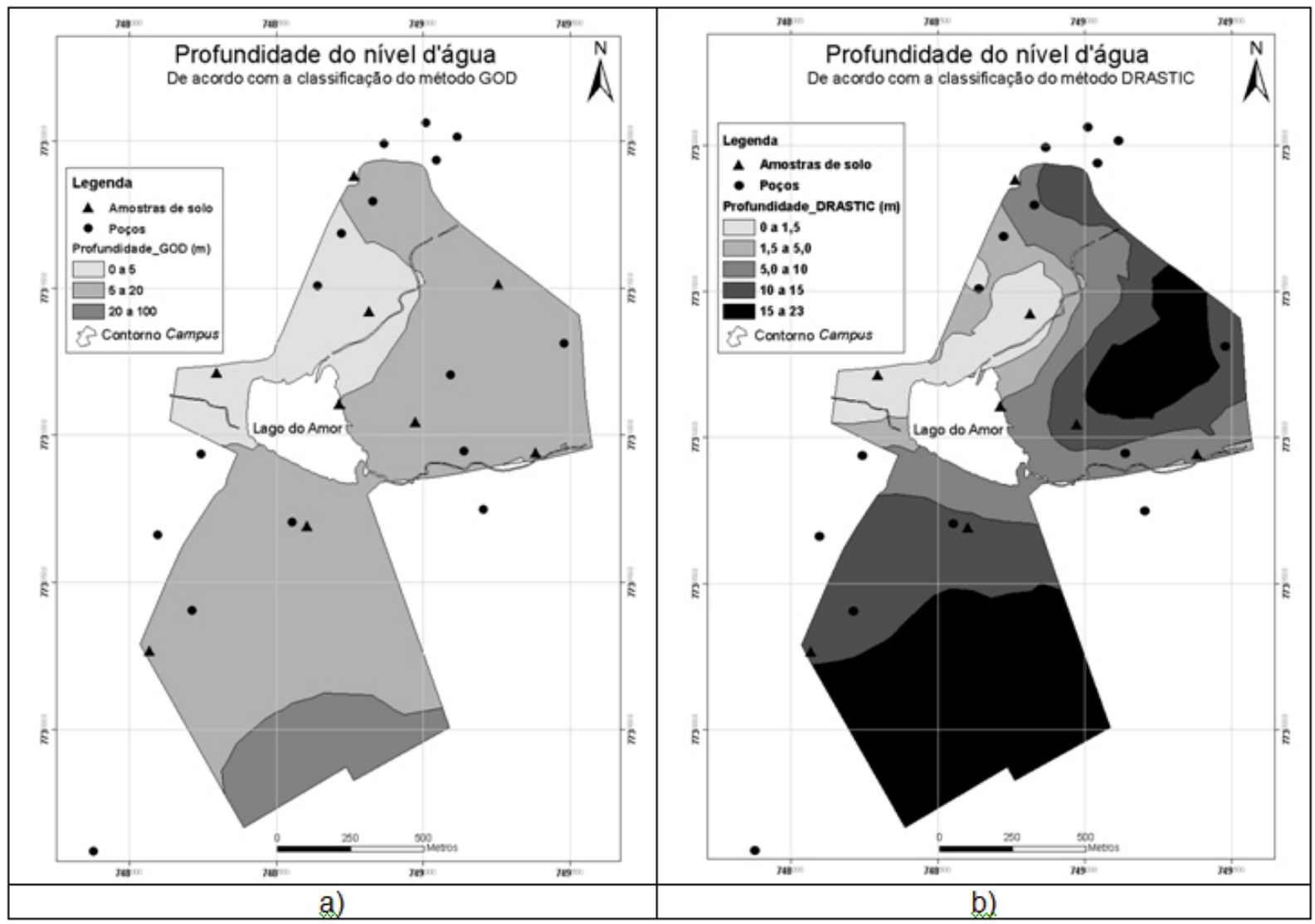

Figura 6: Mapas de profundidade do nivel d'água - GOD (a) e DRASTIC (b)

Figure 6: Ground water depth map - GOD (a) e DRASTIC (b).

Com relação ao mapa de declividade (Figura 7), somente utilizado no método DRASTIC, observa-se que, em geral, a área apresenta baixa declividade, não ultrapassando a faixa de $6 \%$; em alguns pontos localizados, principalmente ao norte do Lago do Amor, estão acima de 18\%. 


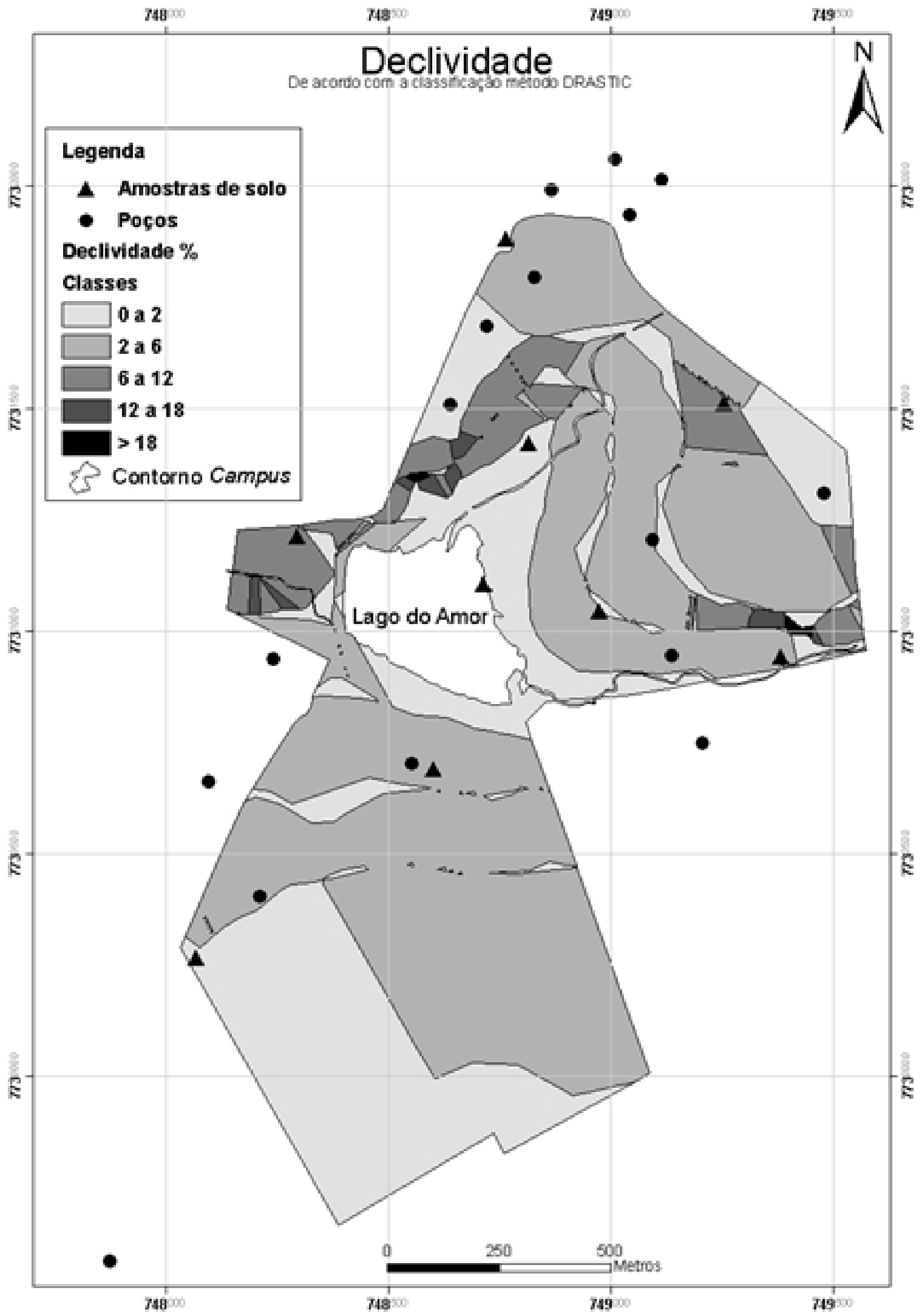

Figura 7: Mapa de declividade da área estudada.

Figure 7: Study area slope map. 
Em relação aos solos, ocorrem, principalmente, solos de alteração de basaltos e, localmente basaltos alterados e sedimentos aluvionares quaternários, próximos às drenagens (Figura 8). A espessura do manto de intemperismo sobre os basaltos é variável, ocorrendo locais com camada de solo de 1 a $2 \mathrm{~m}$, próximo às drenagens, até $12 \mathrm{~m}$, como observado no perfil do poço do Hospital Veterinário (P3) (Figura 3). As principais drenagens ocorrem encaixadas em lineamentos (Figura 8).

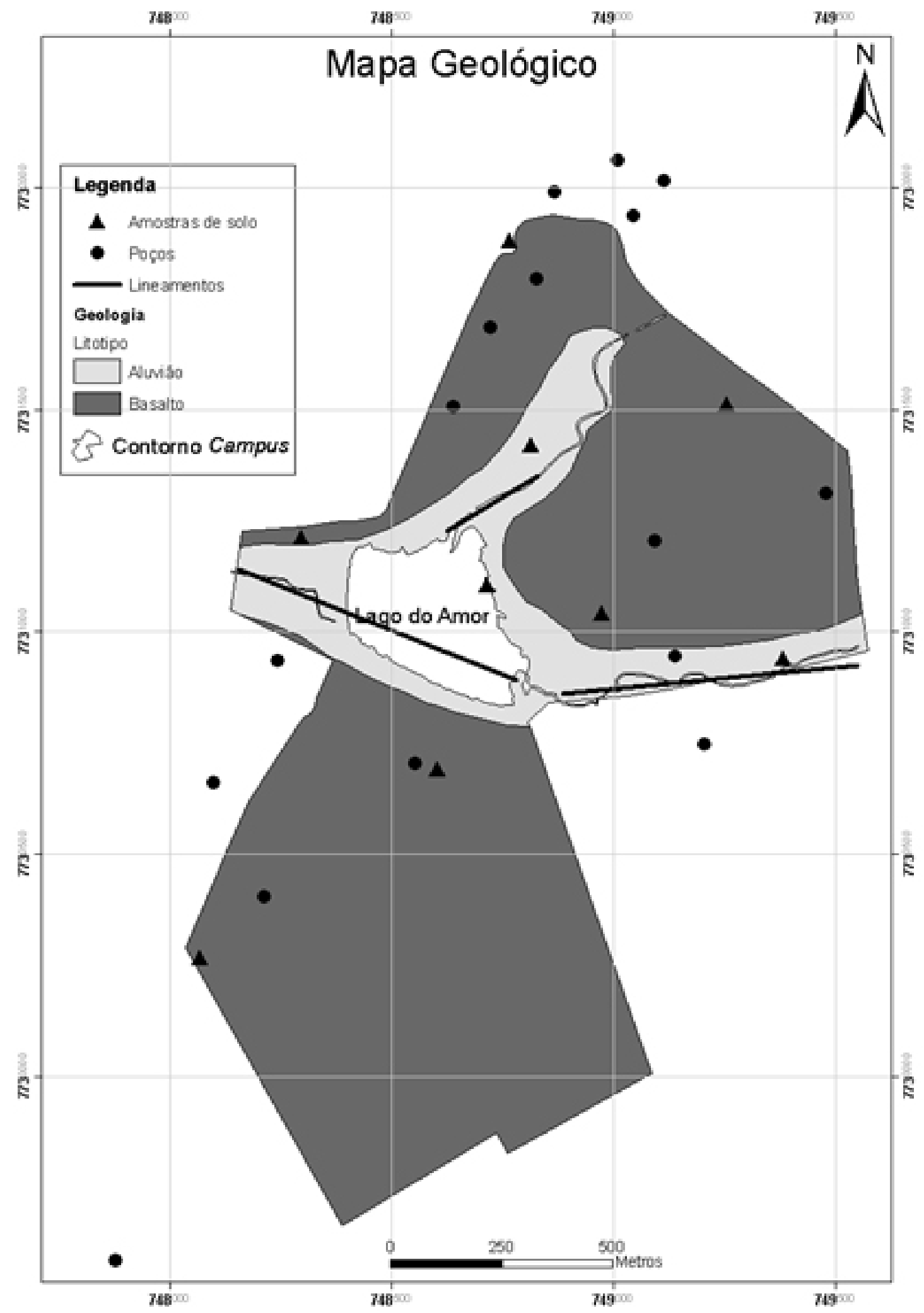

Figura 8: Mapa geológico do Campus UFMS.

Figure 8: Geological map of UFMS'S Campus. 
Pelo método GOD (Figura 9a), resultaram três classes, alta, média e baixa vulnerabilidade, bem definidas e contínuas; as áreas de alta vulnerabilidade se localizam na porção noroesteoeste, nas quais estão instaladas as Faculdades de Medicina e de Odontologia, incluindo o Hospital Universitário, a noroeste, e a oeste, as unidades do curso de Química, incluindo os laboratórios de análises químicas. Em relação a toda a área do Campus, predomina vulnerabilidade média do aqüífero.

No método DRASTIC (Figura 9b), a vulnerabilidade foi definida por quatro classes, alta, moderada, baixa e muito baixa, predominando a média e a baixa. A área com alta vulnerabilidade, coincidente com o método GOD, concentra a maior parte das instalações da área de saúde da universidade, incluindo o Hospital Universitário.

Observa-se que em ambos os métodos os contornos das classes de vulnerabilidade assemelham-se aos mapas de profundidade do nível d'água (Figuras 6 a e 6b), indicando que este parâmetro é o mais influente na área estudada. Isto pode ser atribuído às pequenas variações dos outros atributos como geologia, solos e declividade. A relevância da profundidade do nível d'água foi também observada por Santos et al. (2006) no Aquífero Basáltico, aplicando o método DRASTIC, no município de Londrina, Estado do Paraná.

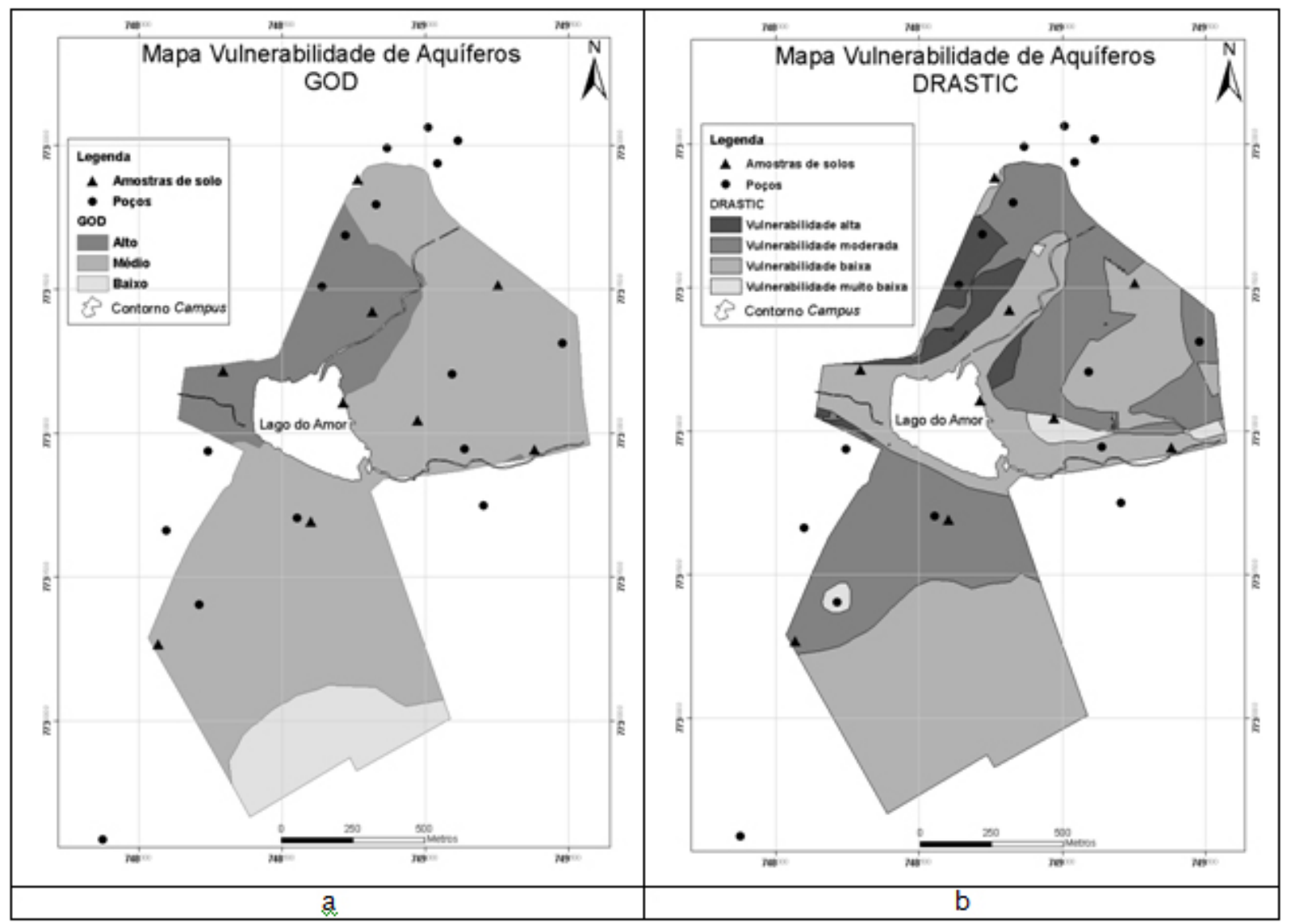

Figura 9: Mapas de vulnerabilidade do Aquífero Basáltico da área estudada-método GOD (a) e DRASTIC (b).

Figure 9: Basaltic Aquifer vulnerability maps in the study area - GOD (a) and DRASTIC (b) methods. 
Embora o método DRASTIC tenha gerado uma classe a mais de vulnerabilidade, de maneira geral, há concordância entre os dois métodos quanto às classes extremas de vulnerabilidade encontradas para a área de estudo: a alta se localiza na porção noroeste e a baixa, na porção sul. A classe de vulnerabilidade 'muito baixa' apresentada pelo método DRASTIC possui área muito restrita no Campus.

O método GOD apresentou um resultado de vulnerabilidade muito próximo ao do método DRASTIC, necessitando, no entanto, de um número menor de parâmetros para sua obtenção, o que implica em um menor custo e tempo para a produção de um levantamento desta natureza.

$\mathrm{Na}$ região noroeste do Campus, concentramse algumas atividades importantes, tais como o hospital universitário e boa parte da estrutura de salas de aula e da administração universitária, além de área vizinha ocupada por diversas atividades comerciais, onde pode haver fontes pontuais de contaminação, tais como as fossas sumidouro e laboratórios, ou outros estabelecimentos na vizinhança, como tanques armazenadores de combustível e postos de gasolina.

A porção sul do Campus, com baixa vulnerabilidade, contém uma reserva de cerrado que contribui para a melhor qualidade da água subterrânea. No entanto, o mapa potenciométrico (Figura 2) indica que poucos são os poços de captação da Universidade influenciados pelo fluxo advindo desta área. A maior parte dos poços localiza-se nas porções noroeste e nordeste do Campus.

Em relação à vulnerabilidade do aquífero subjacente na área estudada, o Sistema Aquífero Guarani (SAG), é influenciada pelo Sistema Aquífero Serra Geral (SASG), uma vez que os poços que atingiram o SAG apresentam níveis estáticos correspondentes aos níveis dos poços perfurados somente no SASG, indicando que localmente a potenciometria do SASG é maior do que a do SAG.

\section{CONCLUSÕES E RECOMENDAÇÕES}

O Aquífero Basáltico, na área do Campus da UFMS em Campo Grande, comporta-se como aquífero livre e é explotado para o suprimento da sua demanda de água. De maneira geral, apresenta vulnerabilidade média à contaminação pelos dois métodos avaliados, o GOD e o DRASTIC, sendo a profundidade do nível d'água o parâmetro que mais influencia a vulnerabilidade do aquífero.

Existem fontes potenciais de contaminação dentro e fora do Campus, principalmente em sua porção noroeste, a qual foi classificada como de vulnerabilidade alta (método GOD) e moderada e alta (método DRASTIC).

Como o nível freático varia de acordo com as estações climáticas e a intensidade de explotação do aquífero, considera-se que a profundidade do nível d'água deve ser monitorada regularmente devido à sua direta associação com a vulnerabilidade do aquífero. Da mesma maneira alguns parâmetros químicos associados à contaminação por fossas, laboratórios de análises químicas e clínicas, hidrocarbonetos, entre outros, também devem ser monitorados para assegurar a qualidade da água que está sendo consumida na região estudada.

Com relação à aplicabilidade dos métodos, o método GOD satisfaz o objetivo de se produzir um mapa de vulnerabilidade para o Campus, visto que além de apresentar concordância com o método DRASTIC demanda um número menor de parâmetros a serem levantados. Isto se traduz em maior rapidez de obtenção de resultados e menor custo aplicado.

\section{REFERÊNCIAS BIBLIOGRÁFICAS}

ALLER, L.; BENNETT, T.; LEHR, J. A.; PETTY R.; HACKETT, G. DRASTIC: A standardized system for evaluating ground water pollution potential using hydrogeological settings. [Washington, D.C.]: U.S. Environmental Protection Agency, 1987. 643p. (EPA Publication 600287035).

ENVIRONMENTAL

SYSTEMS

REASEARCH INSTITUTE - ESRI, Inc. ArcGIS

Professional GIS for the desktop, version 9.3 Software. 2008.
FOSTER, S. Fundamental concepts in aquifer vulnerability pollution risk and protection strategy. In: INTERNATIONAL CONFERENCE OF VULNERABILITY OF SOIL AND GROUNDWATER TO POLLUTANTS, 1987, Noordwijk. Proceedings... The Hague: TNO Committee on Hydrological Research; Bilthoven: National Institute of Public Health and Environmental Hygiene, 1987.

FOSTER, S.; HIRATA, R. Groundwater pollution risk assessment: a methodology using 
available data. Lima, Peru: WHO-PAHO/HPECEPIS Technical Manual, 1988. 81p. (Technical Report).

HIRATA, R. FERNANDES, A. Vulnerabilidade à poluição de aqüíferos. In: FEITOSA, F.A.C.; MANOEL FILHO, J.; FEITOSA, E.C.; DEMETRIO, J.G.A. hidrogeologia, conceitos e aplicações. Rio de Janeiro: CPRM: LABHID. $3^{\mathrm{a}}$ ed. rev. ampl., 2008.

INSTITUTO MUNICIPAL DE PLANEJAMENTO URBANO - PLANURB. Carta geotécnica de Campo Grande. Secretaria Municipal de Planejamento. Prefeitura Municipal de Campo Grande. 24p. 1991.

INSTITUTO NACIONAL DE METEOROLOGIA - INMET 2000 - Dados climáticos. Instituto Nacional de Meteorologia. Disponível em <www.inmet.gov.br $>$. Acesso em 15/03/2008.

LASTORIA, G. Hidrogeologia da Formação Serra Geral no Estado de Mato Grosso do Sul. Instituto de Geociências e Ciências Exatas, UNESP, Rio Claro, Tese de Doutorado, Rio Claro, 133p. 2002.

MINISTÉRIO DAS MINAS E ENERGIA. MME. Projeto Radambrasil. Levantamento de recursos naturais, Folha SF. 21 - Campo Grande. Rio de Janeiro, Ministério das Minas e Energia, v.28, 413p. 1982.

OLIVEIRA, M.A.S. Piezometria do aquífero basáltico. Monografia submetida ao Curso de
Pós-Graduação "Lato Sensu" em Planejamento e Gerenciamento em Recursos Hídricos do Centro de Ciências Exatas e Tecnologia da Universidade Federal de Mato Grosso do Sul, como requisito parcial para obtenção do título de Especialista. 42p. 2003.

SANTOS, M.M.; CAETANO-CHANG, M.R.; CHANG, H.K.; CELLIGOI, A. Avaliação da vulnerabilidade natural à poluição utilizando o Índice DRASTIC em área selecionada na cidade de Londrina (PR). Águas Subterrâneas, v 20, n.1, Jan-Jun, 2006, p. 29-46.

SECRETARIA DE ESTADO DO MEIO AMBIENTE, DO PLANEJAMENTO, DA CIÊNCIA E TECNOLOGIA E INSTITUTO DE MEIO AMBIENTE DE MATO GROSSO DO SUL - SEMAC. Plano Estadual de Recursos Hídricos de Mato Grosso do Sul. Campo Grande, MS: Ed. UEMS, 2010, 194p.

SOARES, W. C. Análise granulométrica do solo do Campus da Universidade Federal de Mato Grosso do Sul, em Campo Grande. 29p. 2004.

SPACE IMAGING. Imagem IKONOS II, de 16 de abril de 2006. Bandas 1, 2, 3 e pancromática. 1 CD ROM.

TAHAL CONSULTING ENGINEERS LTD. e EMPRESA DE SANEAMENTO DE MATO GROSSO DO SUL S. A. - SANESUL - Estudos Hidrogeológicos de Mato Grosso do Sul. Relatório Final, Campo Grande, mapas, v. I, II, IV, 736p. 1998. 